\title{
Fragile X syndrome: Diagnostic and carrier testing
}

Stephanie Sherman, $P h D^{1,2}$, Beth A. Pletcher, $M D^{1,3}$, and Deborah A. Driscoll, $M D^{1,4}$

Key Words: fragile $X$ syndrome, genetic testing, FMR1, X-linked mental retardation

\begin{abstract}
Disclaimer: This guideline is designed primarily as an educational resource for medical geneticists and other health care providers to help them provide quality medical genetic services. Adherence to this guideline does not necessarily assure a successful medical outcome. This guideline should not be considered inclusive of all proper procedures and tests or exclusive of other procedures and tests that are reasonably directed to obtaining the same results. In determining the propriety of any specific procedure or test, the geneticist should apply his or her own professional judgment to the specific clinical circumstances presented by the individual patient or specimen. It may be prudent, however, to document in the patient's record the rationale for any significant deviation from this guideline.
\end{abstract}

The following are the recommendations of the American College of Medical Genetics (ACMG) Professional Practice and Guidelines Committee, convened to assist health care professionals in making decisions regarding genetic diagnosis and testing. The purpose of this document is to provide a brief overview of fragile $X$ syndrome (FXS), and to make recommendations that can serve as general guidelines to aid clinicians in making referrals for diagnostic and carrier testing for this condition. Fragile $X$ syndrome is the most common cause of inherited mental retardation and is caused by a mutation in the X-linked FMR1 gene. DNA studies are used for testing individuals with symptoms of FXS and individuals at risk for carrying the mutation. Genotypes are determined by examining the size of the trinucleotide repeat segment and the methylation status of the FMR1 gene. These guidelines supersede the 1994 ACMG statement of the same name.

\section{INTRODUCTION}

Fragile $\mathrm{X}$ syndrome is the most common cause of inherited mental retardation and is due to a mutation in the X-linked FMR1 gene. Males with fragile X syndrome almost always exhibit mental retardation, usually in the moderate range, and often have characteristic physical features and behavior. Since the mutation is $\mathrm{X}$-linked, males are more severely affected than females. Thus, affected females tend to have mild mental retardation, and have variable associated physical features. (For review of the features of fragile $\mathrm{X}$ syndrome, identification of the gene, and its inheritance pattern, see Warren and Sherman $(2001)^{1}$ and Hagerman and Hagerman (2002)). ${ }^{2}$

\footnotetext{
For the ${ }^{1} A C M G$ Professional Practice and Guidelines Committee; ${ }^{2}$ Emory University, Atlanta, GA; ${ }^{3}$ University of Medicine and Dentistry of New Jersey, Newark, NJ; ${ }^{4}$ University of Pennsylvania Medical Center, Philadelphia, PA

American College of Medical Genetics, 9650 Rockville Pike, Bethesda, MD 20814-3998

Supersedes the 1994 statement of the same name

Go to www.geneticsinmedicine.org for a printable copy of this document.

Approved by the Board of Directors of the American College of Medical Genetics October 26, 2004
}

DOI: 10.1097/01.GIM.0000182468.22666.dd
The mutation leading to over $98 \%$ of cases of fragile $\mathrm{X}$ syndrome is an expansion of an unstable CGG repeat sequence located in the 5' untranslated region (UTR) of the FMR1 gene. ${ }^{3,4}$ There are essentially four allelic forms of the gene with respect to repeat length. They are referred to as common, "gray zone" or intermediate, premutation, and full mutation. The associated repeat sizes for each group are not well-defined and, as such, complicate genetic counseling. The full mutation form of the FMR1 gene consists of over 200 repeats and is abnormally hypermethylated. Consequently, the gene is silenced and no mRNA is produced. The lack of the gene product, FMRP, an RNA-binding protein, is responsible for the mental retardation. ${ }^{5}$ Approximately $1 / 4000$ males have fragile $\mathrm{X}$ syndrome and, by inference, about $1 / 8000$ females have significant features of the syndrome (for review, see Crawford et al. (2001)). ${ }^{6}$ Premutation alleles are defined as long, unmethylated repeat tracks that are unstably transmitted from parent to child. Approximately $1 / 350$ females and $1 / 1000$ males carry premutation alleles in the range of 61-200 repeats. However, this repeat range for premutation alleles is probably too narrowly defined, since unstable alleles with 50 to 60 repeats are sometimes identified in the older generations of families with fragile X syndrome and clearly are "permutation" alleles. Alleles in the intermediate range (41-60) are usually defined by repeat size only. That is, they usually are not associated with known unstable transmission to a full mutation and/or a relative with fragile $\mathrm{X}$ syndrome. Instability may or may not be characteristic of the allele and depends on factors related to the repeat structure (i.e., interruption of CGG repeats by an AGG sequence) and trans-acting factors not yet defined. ${ }^{7-9}$ Thus, the definitions of premutation and intermediate alleles are blurred. Most often a premutation is clinically reported when it is $\geq 55$ repeats. Overall, high repeat number tracks (41-199) are carried by about $4 \%$ of males and $8 \%$ of females of Northern European descent. The prevalence is similar in most other ethnic/racial groups, although there is some variation among populations. ${ }^{10-11}$ 
The clinical consequences of the expanded CGG repeat in the FMR1 gene were thought to be restricted to those with the full mutation (hence the term "full"), namely, overt mental retardation. However, the unmethlyated, long CGG repeat track found in premutation carriers has been associated with specific phenotypes unrelated to fragile X syndrome and unrelated to full mutation carriers. One well recognized consequence for women who carry the premutation allele is an increased risk for premature ovarian failure (POF), clinically defined as the cessation of menses before the age of 40. Among women who carry the premutation, approximately $21 \%$ have POF compared to only $1 \%$ in the general population, or a relative risk of $21 . .^{12}$ Furthermore, approximately $2 \%$ and $14 \%$ of women with isolated POF and familial POF, respectively, carry the premutation allele. This high carrier frequency compares with $0.3 \%$ in the general population. The etiology of the ovarian failure and the risk factors associated with the FMR1 gene are under investigation.

More recently, a significant increase in the risk for a late onset neurodegenerative disorder with tremor/ataxia syndrome (FXTAS) has been identified in men who carry the premutation, and in a smaller proportion of women. ${ }^{13-15}$ The primary clinical symptoms are cerebellar ataxia and intention tremor. Other documented symptoms include cognitive deficits such as short-term memory loss, executive function deficits, cognitive decline, parkinsonism, peripheral neuropathy, lower limb proximal muscle weakness and autonomic dysfunction. ${ }^{14}$ Initial studies indicate a penetrance of combined tremor and ataxia among men ages 50 years or more with the premutation of about $20-40 \% .^{14-17}$ Overall, these men have an estimated 13-fold increase in these symptoms compared with noncarriers. ${ }^{15}$ However, more research is needed to accurately define the age-related penetrance and relative risks for genetic counseling purposes.

The unique inheritance pattern of this X-linked mutation leads to some sensitive issues related to an individual's knowledge of his or her own carrier status as well as cognizance of mutation status in other family members. Most often, the fragile $\mathrm{X}$ mutation segregating in a family is identified through a child with fragile $\mathrm{X}$ syndrome due to the full mutation, with symptoms such as developmental delay or mental retardation. Thus, premutation carrier status associated with late onset disorders may be inadvertently uncovered in an individual who is tested as part of a family study. For late onset disorders such as these, ethical issues arise as to whether or not a given individual wishes to know his or her carrier status. As health professionals become more aware of the premutation-associated phenotypes of premature ovarian failure and FXTAS, more families are likely to be identified under other circumstances.

In general, the fragile $\mathrm{X}$ mutation follows the traditional rules of X-linked inheritance: Half of the offspring of carrier mothers will receive the mutation and all the daughters but none of the sons of carrier fathers receive the mutation. However, the risk of expansion of the CGG repeats in a premutation allele to a full mutation overlays the transmission pattern of this syndrome. Expansion of the premutation to the full mutation during transmission through a carrier woman is positively correlated with the size of the woman's repeat. ${ }^{9}$ The smallest repeat size to expand to a full mutation in one generation is 59 repeats. ${ }^{9}$ The risk of expansion to the full mutation from carrier men to their daughters is rare, but has been reported. ${ }^{18}$ That is, premutation males pass on the premutation to their daughters, typically with only small expansions or contractions.

Prediction of the severity of the symptoms of fragile X syndrome is limited. Severity tends not to be influenced by the number of repeats within a full mutation allele, since once the full mutation allele is over 200 repeats and is methylated, no gene product is made. A minority of males with a full mutation have some alleles that are unmethylated; they are known as "methylation mosaics." Such alleles may produce FMRP, although at lower levels than low repeat alleles, presumably due to translation inefficiency. ${ }^{19}$ In addition, there are males who are mosaic for pre- and full mutation alleles. Males with these mosaic patterns are less severely affected, on average, than those with only full mutation alleles. However, the range of severity overlaps. For females who carry the full mutation, the percentage of active $\mathrm{X}$ chromosomes with the normal repeat allele compared to the full mutation allele can modify the severity of the symptoms, as expected for any X-linked condition. However, it is difficult to predict severity for an individual carrier based on this activation ratio. On average, about onethird to one-half of females who carry the full mutation is significantly affected with fragile X syndrome.

DNA studies are used to test for fragile X syndrome. Genotypes of individuals with symptoms of FXS and individuals at risk for carrying the mutation can be determined by examining the size of the trinucleotide repeat segment and the methylation status of the FMR1 gene. Two main approaches are used: polymerase chain reaction (PCR) and Southern blot analysis. PCR analysis utilizes flanking primers to amplify a fragment of DNA spanning the repeat region. Thus, the sizes of the PCR products are indicative of the approximate number of repeats present in each allele of the individual being tested. The efficiency of the PCR reaction is inversely related to the number of CGG repeats, so large mutations are more difficult to amplify and may fail to yield a detectable product in the PCR assay. This, and the fact that no information is obtained about the FMR1 methylation status, are limitations of the PCR approach. On the other hand, PCR analysis permits accurate sizing of alleles in the normal, the "gray zone," and the premutation size ranges on small amounts of DNA in a relatively short turnaround time. Also, the assay is not affected by skewed Xchromosome inactivation.

FMR1 analysis by Southern blotting allows a crude measure of the size of the repeat segments and an accurate assessment of the methylation status to be assayed simultaneously. A methylation-sensitive restriction enzyme that fails to cleave 
methylated sites is used to distinguish between methylated and unmethylated alleles. Southern blot analysis is more labor intensive than PCR and requires larger quantities of genomic DNA. Southern blot analysis accurately detects alleles in all size ranges, but precise sizing is not possible. Furthermore, highly skewed inactivation of the X-chromosome harboring the premutation could lead to the lack of resolution of the premutation allele. Laboratories should have both methods available and perform the types of analysis or combination of analyses that are most appropriate under the clinical circumstances.

In a small number of individuals with FXS, mechanisms other than trinucleotide expansion, such as deletion or point mutation, are responsible for the syndrome. In these cases, linkage studies, cytogenetic, sequencing and/or assays designed to identify rare mutations and deletions may provide important information for relatives.

\section{RECOMMENDATIONS FOR DIAGNOSTIC TESTING}

The purpose of these recommendations is to provide general guidelines to aid clinicians in making referrals for testing the repeat region of the FMR1 gene.

\section{Individuals for Whom Testing Should Be Considered}

\section{Fragile $X$ syndrome:}

- Individuals of either sex with mental retardation, developmental delay, or autism, especially if they have (a) any physical or behavioral characteristics of fragile X syndrome, (b) a family history of fragile X syndrome, or (c) male or female relatives with undiagnosed mental retardation.

- Individuals seeking reproductive counseling who have (a) a family history of fragile X syndrome or (b) a family history of undiagnosed mental retardation.

- Fetuses of known carrier mothers.

- Affected individuals or their relatives in the context of a positive cytogenetic fragile $\mathrm{X}$ test result who are seeking further counseling related to the risk of carrier status among themselves or their relatives. The cytogenetic test was used prior to the identification of the FMR1 gene and is significantly less accurate than the current DNA test. DNA testing on such individuals is warranted to accurately identify premutation carriers and to distinguish premutation from full mutation carrier women.

\section{Ovarian dysfunction:}

- Women who are experiencing reproductive or fertility problems associated with elevated follicle stimulating hormone (FSH) levels, especially if they have (a) a family history of premature ovarian failure, (b) a family history of fragile $\mathrm{X}$ syndrome, or (c) male or female relatives with undiagnosed mental retardation.

\section{Tremor/ataxia syndrome:}

- Men and women who are experiencing late onset intention tremor and cerebellar ataxia of unknown origin, especially if they have (a) a family history of movement disorders, (b) a family history of fragile $\mathrm{X}$ syndrome, or (c) male or female relatives with undiagnosed mental retardation.

\section{Common Problems That Occur with the FMR1 Diagnostic Test}

There are several issues related to the FMR1 DNA test results that should be described. A difficult situation occurs when a premutation allele is identified in a patient who has been referred because of symptoms of the fragile X syndrome, primarily developmental delay or mental retardation. There are several explanations for this finding: 1) the symptoms and the premutation carrier status occur together by chance; 2) the phenotype is caused by the premutation allele; 3 ) the individual is a mosaic pre/full mutation carrier and the full mutation allele cannot be detected in peripheral blood. If the allele identified is large ( $>100$ repeats), the third explanation may be the most viable, especially if the parent of the patient also carries a large pre or full mutation allele. The first and second explanations are hard to distinguish and research is ongoing to determine if the premutation allele is responsible for overt symptoms of the fragile $\mathrm{X}$ syndrome.

Identification of alleles in the gray zone can also be problematic in terms of establishing the risk for expansion in future generations. One method to determine instability is to obtain biological samples from other family members to examine stability of the allele during transmission from parent to offspring.

Lastly, carriers with pre/full mosaic pattern are especially difficult to identify with just one DNA method. PCR testing could identify the premutation, but not the full mutation, leading to a different risk assessment for the fragile X syndrome, FXTAS or POF. Thus, in a clinical setting, it may be prudent to conduct Southern blot analysis even if a premutation allele is identified.

\section{POPULATION SCREENING}

Population carrier screening is not recommended at this time except as part of a well-defined clinical research protocol. While the DNA test is very accurate, it is important to ensure that effective means are in place to adequately counsel tested populations about the meaning and implications of these results. The nature of different phenotypes associated with the FMR1 mutation in its premutation and full mutation forms and the inheritance pattern are complex. Furthermore, the approach to genetic counseling for different phenotypes including early onset disorder of mental retardation, adult onset of premature ovarian failure, and a late onset disorder associated with neurodegeneration, all within the same family has not yet been addressed at a clinical level much less a population screening level. Clearly, considerable work must be done before instituting general population screening. 


\section{APPROACHES TO TESTING}

- DNA analysis is the method of choice if one is testing specifically for fragile $\mathrm{X}$ syndrome and associated trinucleotide repeat expansion in the FMR1 gene.

- For isolated cognitive impairment, DNA analysis for fragile $\mathrm{X}$ syndrome should be performed as part of a comprehensive genetic evaluation that includes routine cytogenetic analysis. Cytogenetic studies are critical, since constitutional chromosome abnormalities have been identified as frequently or more frequently than fragile $\mathrm{X}$ mutations in mentally retarded individuals referred for fragile $\mathrm{X}$ testing.

- For individuals who are at risk due to an established family history of fragile X syndrome, DNA testing alone is sufficient. If the diagnosis of the affected relative was based on previous cytogenetic testing for fragile X syndrome, at least one affected relative should have DNA testing.

- Prenatal testing of a fetus should be offered when the mother is a known carrier to determine whether the fetus inherited the normal or mutant FMR1 gene. Ideally DNA testing should be performed on cultured amniocytes obtained by amniocentesis after 15 weeks' gestation. DNA testing can be performed on chorionic villi obtained by CVS at 10 to 12 weeks' gestation, but the results must be interpreted with caution because the methylation status of the FMR1 gene is often not yet established in chorionic villi at the time of sampling. A follow-up amniocentesis may be necessary to resolve an ambiguous result.

- If a woman has ovarian failure before the age of 40 , DNA testing for premutation size alleles should be considered as part of the infertility evaluation and prior to in vitro fertilization.

- If a patient has cerebellar ataxia and intentional tremor, DNA testing for premutation size alleles, especially among men, should be considered as part of the diagnostic evaluation.

\section{References}

1. Warren ST, Sherman SL. The fragile X syndrome. In: Scriver, C. R., Beaudet, A. L., Sly, W. S., and Valle, D., editors. Metabolic Basis of Inherited Disease, 8th ed. New York: McGraw-Hill, 2001; pp 1257-1289.

2. Hagerman RJ, Hagerman PJ, editors. Fragile X Syndrome: Diagnosis, Treatment, and Research, 3rd ed. Baltimore: Johns Hopkins University Press, 2002.

3. Fu YH, Kuhl DP, Pizzuti A, Pieretti M, et al: Variation of the CGG repeat at the fragile X site results in genetic instability: resolution of the Sherman paradox. Cell 1991;67:1047-1058.

4. Verkerk AJ, Pieretti M, Sutcliffe JS, Fu YH, et al: Identification of a gene (FMR-1) containing a CGG repeat coincident with a breakpoint cluster region exhibiting length variation in fragile X syndrome. Cell 1991;65:905-914.

5. Ashley CTJ, Wilkinson KD, Reines D, Warren ST. FMR1 protein: conserved RNP family domains and selective RNA binding. Science 1993;262:563-566.

6. Crawford DC, Acuna JM, Sherman SL. FMR1 and the fragile X syndrome: human genome epidemiology review. Genet Med 2001;3:359-371.

7. Sullivan AK, Crawford DC, Scott EH, Leslie ML, Sherman SL. Paternally transmitted FMR1 alleles are less stable than maternally transmitted alleles in the common and intermediate size range. Am J Hum Genet 2002;70:1532-1544.

8. Crawford DC, Wilson B, Sherman SL. Factors involved in the initial mutation of the fragile X CGG repeat as determined by sperm small pool PCR. Hum Mol Genet 2000;9:2909-2918.

9. Nolin SL, Brown WT, Glicksman A, Houck GE, Jr., et al: Expansion of the fragile X CGG repeat in females with premutation or intermediate alleles. Am J Hum Genet 2003;72:454-464.

10. Crawford DC, Meadows KL, Newman JL, Taft LF, et al: Prevalence of the fragile X syndrome in African Americans. Am J Med Genet 2002;110:226-233.

11. Crawford DC, Meadows KL, Newman JL, Taft LF, et al: Prevalence and phenotype consequence of FRAXA and FRAXE alleles in a large, ethnically diverse, special education-needs population. Am J Hum Genet 1999;64:495-507.

12. Sherman SL. Premature ovarian failure in the fragile X syndrome. Am J Med Genet 2000;97:189-194.

13. Hagerman RJ, Leehey M, Heinrichs W, Tassone F, et al: Intention tremor, parkinsonism, and generalized brain atrophy in male carriers of fragile X. Neurology 2001; 57:127-130.

14. Jacquemont S, Hagerman RJ, Leehey M, Grigsby J, et al: Fragile X premutation tremor/ataxia syndrome: molecular, clinical, and neuroimaging correlates. Am J Hum Genet 2003;72:869-878.

15. Jacquemont S, Hagerman RJ, Leehey MA, Hall DA, et al: Penetrance of the fragile $\mathrm{X}$-associated tremor/ataxia syndrome in a premutation carrier population. JAMA 2004;291:460-469.

16. Rogers C, Partington MW, Turner GM. Tremor, ataxia and dementia in older men may indicate a carrier of the fragile X syndrome. Clin Genet 2003;64:54-56.

17. Smits A, van der Bruggen W, Sistermans E, Kiemeney B, Reneir W, Kremer B. Striking neurological symptoms in normal transmitting males of the fragile X syndrome. 8th International Fragile X Conference, July 2002, Conference Proceedings.

18. Zeesman S, Zwaigenbaum L, Whelan DT, Hagerman RJ, Tassone F, Taylor SA Paternal transmission of fragile X syndrome. Am J Med Genet 2004;129A:184-189.

19. Feng Y, Zhang F, Lokey LK, Chastain JL, et al: Translational suppression by trinucleotide repeat expansion at FMR1. Science 1995;268:731-734. 